\title{
A PRODUÇÃO DO CONHECIMENTO CIENTÍFICO EM GINÁSTICA
}

\author{
Ana Maria Pereira, Universidade Estadual de Londrina, Paraná - Brasil \\ Thaís Nogueira de Andrade, Universidade Estadual de Londrina, Paraná - Brasil \\ Marilene Cesário, Universidade Estadual de Londrina, Paraná - Brasil
}

\begin{abstract}
RESUMO
Esta pesquisa investigou a produção do conhecimento na área de Educação Física, especificamente em Ginástica, tendo como referência as dissertações de mestrado e as teses de doutorado produzidas em nível nacional, que se encontram disponíveis nas bases de dados da Biblioteca Digital de Teses e Dissertações (BDTD), da Biblioteca Digital da UNICAMP, do Sistema de Publicação Eletrônica de Teses e Dissertações NUTESES, e também, da Biblioteca Digital de Teses e Dissertações da USP. Realizou-se um levantamento das produções teóricas na área, bem como a ordenação dos estudos de Ginástica produzidos e disseminados na primeira década do século XXI. Para alcançar tal propósito realizou-se uma pesquisa de natureza qualitativa e quantitativa, tendo como instrumento a análise de conteúdos dos resumos e da introdução dessa produção, com objetivo de organizar o material em temáticas. Constatamos nessa pesquisa a predominância de temáticas relacionadas à saúde, fitness e esporte, o que indica a influência da biologização, sob o paradigma positivista, na produção da área, mas também, encontramos pesquisas em educação, formação humana e aspectos históricos, o que revela tendências de uma concepção crítica e superadora.
\end{abstract}

Palavras-Chave: Ginástica; Produção teórica; Educação Física.

\section{THE PRODUCTION OF SCIENTIFIC KNOWLEDGE IN GYMNASTICS}

\begin{abstract}
This study investigated the production of knowledge on the field of Physical Education, specifically in Gymnastics, using Master's and doctoral dissertations written nationwide as reference. These are available in the databases of Biblioteca Digital de Teses e Dissertações (BDTD), UNICAMP's Biblioteca Digital, Sistema de Publicação Eletrônica de Teses e Dissertações NUTESES, and USP's Biblioteca Digital de Teses e Dissertações. A survey of the literature in this field was done, and the studies on Gymnastics produced and disseminated in the first decade of the $21^{\text {st }}$ century were organized. For this purpose, a qualitative and quantitative approach to research was adopted. An analysis of the contents of the literature abstracts was conducted aiming at organizing the material into themes. It was verified that themes related to health, fitness and sports were predominant, which indicates the influence of the biologization, under the positivist paradigm, on the production in the field. Themes such as education, human education, and historical aspects were also found, which reveals tendencies towards a critical and overcoming conception.
\end{abstract}

Key-Words: Gymnastics; Theoretical production; Physical Education. 


\section{LA PRODUCCIÓN DEL CONOCIMIENTO CIENTÍFICO EN GIMNASIA}

\section{RESUMEN}

Este estudio investigó la producción de conocimiento en el área de Gimnasia, con referencia a las disertaciones y tesis doctorales producidas en el ámbito nacional, que están disponibles en las bases de datos de la Biblioteca Digital de Tesis y Disertaciones (BDTD), en la Biblioteca Digital de la UNICAMP, en Sistema de Publicación de Tesis NUTESES y la Biblioteca Digital de Tesis y Disertaciones de la USP. Para lograr este objetivo se realizó una investigación cualitativa y cuantitativa, como un instrumento que tiene un análisis de contenido de los resúmenes de la producción, con el fin de organizar el material en los temas. Después de la recolección de datos se inició una fase de análisis de contenido. Para que el uso, en particular, pre-análisis, la descripción analítica y la interpretación inferencial. Se encontró que el predominio de temas de investigación relacionados con la salud, condición física y el deporte, lo que indica la influencia de la matriz teórica positivista de la zona de producción, pero también nos encontramos estudios en la educación, los aspectos humanos e históricos, que revelan tendencias diseño críticos y sobrecogedor.

Palabras-Clave: Gimnasia; La producción teórica; Educación Física. 


\section{A PROdUÇÃo do CONHECIMENTO EM EDUCAÇÃo FÍSICA/ GINÁSTICA NO BRASIL}

Observa-se que a produção do conhecimento em Educação Física no Brasil está atrelada aos programas de Pós-graduação, principalmente os de Stricto Sensu. No Brasil, nos anos de 1980, estes programas começaram a ser organizados pelas Universidades de São Paulo e Federal de Santa Maria e, na seqüência, por outras instituições, uma vez que até então, a formação de recursos humanos na área era realizada no exterior ou nos programas de Pósgraduação em educação.

Todavia, destacamos que nos últimos 20 anos a produção do conhecimento cresceu muito, no âmbito da Educação Física, e esta produção é realizada em sua maioria em universidades públicas, sendo estas federais e estaduais.

A questão para refletirmos neste trabalho não se restringe apenas ao crescimento da produção científica em Educação Física, mas sim no tipo de produção que está sendo desenvolvida em uma de suas áreas específica, nomeadamente, a Ginástica. O interesse é saber o que está sendo produzido no âmbito da Ginástica. De outro modo, pretendemos saber qual o objeto das pesquisas científicas em Ginástica.

Para tal, fez-se necessário realizar um levantamento da produção científica tendo em vista conhecer a realidade da Ginástica no Brasil. A Ginástica tem sido explorada como objeto de pesquisa há pouco tempo, nomeadamente, a partir das últimas décadas do século passado.

A Ginástica no passado tinha tendência a aproximar-se de um movimento restrito traduzido numa práxis imitativa, que nada mais é do que uma prática direcionada ao caráter funcional e orgânico do ser humano, pautada nas ciências biológicas, com finalidades de cuidar do corpo, da higiene e da saúde.

O fato é que no final do século passado toda a Educação Física entrou em crise e passou por um processo de crítica, seguido de revisão de seus pressupostos e fundamentos epistemológicos, ontológicos e metodológicos. A Educação Física e, por extensão, a Ginástica tem reclamado por mudanças e por revisão no que se refere ao seu conceito e a sua definição, ao campo de atuação e à intervenção metodológica. Cesário e Pereira ${ }^{1}$ destacam que a Conexões: revista da Faculdade de Educação Física da UNICAMP, Campinas, v. 10, n. Especial, p. 56-79, dez. 2012.58 ISSN: 1983-9030 
Ginástica também tem questionado a sua práxis imitativa, decorrente da concepção de humano centrado no dualismo cartesiano e, ainda, de seu marco teórico oriundo das ciências médicas e de sua prática advinda do militarismo.

Há que considerar uma motricidade humana ampliada no âmbito da Ginástica, sendo este mais consistente, abrangente, complexo e legítimo às questões referentes à história, à filosofia, à política e à cultura, para refutar o movimento restrito, que fragmenta e reduz seus estudos à área biológica, especificamente, a do físico tão só.

Nos últimos vinte anos os movimentos inovadores da Educação Física, defenderam uma reorganização ontológica em que considera o humano como um ser complexo e inteiro. E também, uma reorganização metodológica afinada a uma práxis que se contrapõe frontalmente aos fundamentos básicos da exercitação mecânica do corpo físico ou ao fenômeno esportivo como fim em si mesmo ou de uma prática exclusiva. Estes movimentos inovadores têm ocupado cada vez mais espaço nas discussões das atividades gímnicas, essencialmente daquelas de cunho pedagógico, que trata das práxis da motricidade/corporeidade, principalmente na escola.

Enfim, as pesquisas em Ginástica estão conectadas a quais interesses? Quais os objetivos dessa produção? Serão os fazeres e os saberes dos âmbitos esportivo/competitivo, de demonstração, de qualidade de vida, saúde e fítness e, também, a formação e educação do ser humano?

Considerando a relevância da Pós-graduação Stricto-Sensu na produção do conhecimento no Brasil fez-se necessário realizar um levantamento das dissertações de mestrado e das teses de doutorado concluídas sobre a produção do conhecimento no âmbito da Educação Física, no período de 2000 a 2009, especificamente, da Ginástica. E posteriormente, a organização desta produção por temas convergentes.

Tivemos como objetivo levantar a produção do conhecimento em Ginástica, nomeadamente, das dissertações de mestrado e das teses de doutorado produzidas em nível nacional. Optamos em analisar os resumos e a introdução das dissertações e das teses, com fins de identificar, o conteúdo, ou seja, o constructo teórico presentes nestas pesquisas. Desse modo, iniciou-se a Conexões: revista da Faculdade de Educação Física da UNICAMP, Campinas, v. 10, n. Especial, p. 56-79, dez. $2012 . \quad 59$ ISSN: 1983-9030 
sistematização da produção agrupando as dissertações e as teses por temáticas e objetivos convergentes.

\section{O PERCURSO METODOLÓGICO DA PESQUISA}

Para cumprir nossos objetivos realizou-se uma pesquisa de natureza qualitativa e quantitativa, primeiramente, de caráter documental conforme explica Gil, ${ }^{2}$ visando o levantamento da produção acadêmica de Pós-graduação Stricto Sensu sobre Ginástica, produções estas disponíveis em bancos de informações on line. Posteriormente, dedicamos às análises dos conteúdos dos resumos e da introdução dessa produção na lógica sugerida por Bardin. ${ }^{3}$

Para este estudo de levantamento da produção do conhecimento em Ginástica, nomeadamente, das dissertações e das teses produzidas em nível nacional delimitou-se um período de uma década, especificamente, do ano 2000 até 2009 nos bancos de dados da Biblioteca Digital de Teses e Dissertações (BDTD), Biblioteca Digital da (UNICAMP), no Sistema de Publicação Eletrônica de Teses e Dissertações (NUTESES) e na Biblioteca Digital de Teses e Dissertações da (USP).

Primeiro recorremos ao Banco online de Dissertações e Teses do Portal da Coordenação de Aperfeiçoamento de Pessoal de Nível Superior - CAPES. ${ }^{4}$ Este portal oferece ao público o acesso ao catálogo de pesquisas, no qual se podem buscar informações sobre autor, assunto, instituição, ano de publicação e níveis (mestrado ou doutorado).

No Portal CAPES ${ }^{4}$ nos deparamos com algumas adversidades, como por exemplo, não conter todos os trabalhos na íntegra. Todavia, no mesmo portal, encontramos diversas bases de busca, uma delas a Biblioteca Digital de Teses e Dissertações (BDTD). ${ }^{5}$ Nesta base de dados temos trabalhos em nível nacional, sendo grande maioria dispostos na íntegra. Então, nossa

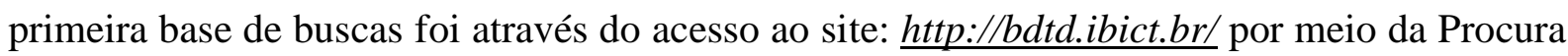
Avançada utilizando a palavra-chave: Ginástica.

Na continuidade da pesquisa escolhemos a Biblioteca Digital da UNICAMP ${ }^{6}$ através do site: http:/www.bibliotecadigital.unicamp.br/, fazendo necessário à realização de um cadastro. Foi utilizada a palavra chave Ginástica para buscar os trabalhos. 
A etapa seguinte da pesquisa ocorreu buscas no Sistema de Publicação Eletrônica de Teses e Dissertações NUTESES, ${ }^{7}$ no site http://www.nuteses.ufu.br/. A palavra chave utilizada para a busca também foi Ginástica.

Na etapa final foi utilizada a Biblioteca Digital de Teses e Dissertações da USP $^{8}$ no site http://www.teses.usp.br/. Também utilizando o termo: Ginástica como palavra chave.

As pesquisas foram salvas em pastas distintas: níveis mestrado e doutorado. Foram criados subpastas para cada nível agrupando as pesquisas em categorias convergentes: esporte, lazer e qualidade de vida, saúde, fítness, história, necessidades especiais, formação profissional, formação e educação do ser humano e mídia. Organizamos uma planilha do Microsoft Office Excel para facilitar o acesso aos mesmos no decorrer da realização da análise de conteúdo de nossa pesquisa.

Faz-se necessário explicitar que na Biblioteca Digital da UNICAMP, no Sistema de Publicação Eletrônica de Teses e Dissertações NUTESES e na Biblioteca Digital de Teses e Dissertações da USP, encontramos trabalhos que já haviam sido encontrados na primeira base de buscas, a BDTD. Portanto, os trabalhos repetidos foram desconsiderados.

Após coleta de dados iniciou-se a fase de análise do conteúdo. Para isso utilizamos o suporte metodológico sugerido por Bardin, ${ }^{3}$ nomeadamente, a pré-análise, a descrição analítica e a interpretação inferencial.

A organização do material favoreceu a pré-análise das pesquisas levantadas on-line, o que possibilitou o agrupamento das categorias. Procedimentos como classificação dos conteúdos levantados indicaram as primeiras categorias, chamadas de empíricas, abstraídas após a leitura dos resumos dos trabalhos.

Numa fase posterior realizamos a interpretação inferencial com objetivo de alcançar maior consistência, analisamos os resumos e também a introdução das pesquisas efetivando o processo de interpretação com o objetivo de reconhecer as categorias centrais dos trabalhos e identificar qual o domínio da produção do conhecimento em Ginástica. Foi um momento de movimento entre o geral da produção levantada e o particular identificado em cada artigo. 


\section{A GINÁSTICA BRASILEIRA NA PRIMEIRA DÉCADA DO SÉCULO XXI}

A presente pesquisa desvela quais são os interesses dos pesquisadores envolvidos com as atividades gíminicas, ou seja, sob qual identidade acadêmica se pautam as produções. Nas buscas on-line foram encontrados diversos trabalhos, entretanto, após leitura dos mesmos notou-se que alguns deles não tinham relação direta com o assunto buscado, estes foram desconsiderados. O critério para a seleção foi utilizar os trabalhos que tratam diretamente da temática Ginástica, uma vez que este é o tema central da nossa pesquisa.

Na BDTD, encontramos 49 (quarenta e nove) dissertações de mestrado e 06 (seis) teses de doutoramento. Na Biblioteca Digital da UNICAMP foram encontrados 23 (vinte e três) pesquisas, sendo 16 (dezesseis) dissertações e 07 (sete) teses. No Sistema de Publicação Eletrônica de Teses e Dissertações NUTESES constavam 17 (dezessete) dissertações de mestrado. E na Biblioteca Digital de Teses e Dissertações da USP foram encontradas 05 (cinco) dissertações de mestrado.

Ao efetuarmos as análises destas dissertações e teses constatamos que a Ginástica está conectada a diferentes interesses, dessa forma com vários objetivos e finalidades. A literatura da área em questão aponta que existe uma grande diversidade quando se trata de Ginástica. Souza ${ }^{9}$ apresentou uma classificação das atividades gímnicas, com objetivos diferenciados. A autora reuniu em 05 (cinco) grupos os diferentes tipos de Ginástica, considerando os seus diferentes campos de atuação, tais como: 1) Ginásticas de Condicionamento Físico (engloba todas as modalidades com o objetivo de aquisição ou manutenção da condição física do indivíduo normal ou não atleta); 2) Ginásticas de Competição (modalidades competitivas, práticas gímnicas que se tornaram ginásticas esportivas); 3) Ginásticas Fisioterápicas (utilizadas na prevenção ou tratamento de doenças); 4) Ginásticas de Conscientização Corporal (reúnem as técnicas alternativas ou ginásticas suaves); 5) Ginásticas de Demonstração (baseiam-se na não competitividade e objetiva a interação e a integração sociais entre os participantes; é representada pela Ginástica para Todos).

Neste estudo em questão notamos que o interesse dos pesquisadores perpassa pelos diferentes Conexões: revista da Faculdade de Educação Física da UNICAMP, Campinas, v. 10, n. Especial, p. 56-79, dez. 2012.62 ISSN: 1983-9030 
tipos de Ginástica existentes, mas também depende da intencionalidade particular dos indivíduos envolvidos. Observamos os mais variados tipos de Ginástica ligados a diferentes temáticas e/ou assuntos.

Demonstraremos no quadro abaixo as categorias encontradas a partir das análises dos resumos e da introdução das dissertações e teses.

Quadro 1 - Categorias levantadas nas bases BDTD, Biblioteca Digital da UNICAMP, Sistema de Publicação Eletrônica de Teses e Dissertações NUTESES e Biblioteca Digital de Teses e

Dissertações da USP.

\begin{tabular}{llll}
\hline \multirow{2}{*}{ Quantidade } & \multicolumn{2}{c}{ CATEGORIAS } & \\
\hline 19 & DISSERTAÇÕES & Quantidade & TESES \\
16 & Fitness & 02 & Esportiva \\
14 & Saúde & 02 & Formação Profissional \\
08 & Esportiva & 02 & Aspectos Históricos \\
04 & Escolar & 01 & Escolar \\
03 & Lazer e Qualidade de Vida & 01 & Formação Humana \\
03 & Aspectos Históricos & 01 & Necessidades Especiais \\
01 & Formação Profissional & 01 & Saúde \\
01 & Necessidades Especiais & & \\
\hline
\end{tabular}

Ao analisarmos todas as categorias observou-se uma quantidade maior de dissertações de mestrado em relação às teses de doutoramento. Infere-se que este fato ocorre devido ao nível de exigência para inserir e concluir cursos de doutorado e, também, porque há mais cursos de mestrado no país em comparação com o número de doutoramento.

- Fitness: compreende os estudos realizados sobre a Ginástica no âmbito das academias.

- Saúde: a Ginástica que objetiva a aquisição, manutenção, aprimoramento ou recuperação da saúde.

- Esportiva: remete aos trabalhos elaborados com objetivo de aprimorar o conhecimento da Ginástica esportiva, no âmbito da competição e do treinamento.

- Escolar: refere-se aos estudos que investigam a Ginástica como conhecimento a ser tratado e ensinado pela Educação Física no âmbito das escolas, com fins educativos.

- Lazer e Qualidade de Vida: estudos que abordam a Ginástica como 
forma de lazer, ocupação tempo livre, ou seja, instrumento que leva a melhoria da qualidade de vida.

- História: trabalhos que objetivam a reflexão do percurso da Ginástica no decorrer da História da humanidade.

- Formação Humana: ginástica como meio de transmissão de valores éticos e morais seja qual for o âmbito onde será realizada.

- Formação Profissional: a Ginástica como um saber/área do conhecimento que o professor de Educação Física precisa apropriar. Estudos do ensino da Ginástica nos currículos do curso das instituições de ensino superior.

- Pessoas com Necessidades Especiais: pesquisas relacionadas aos programas adaptados para pessoas portadoras de necessidades especiais. Existem estudos que mostram possíveis propostas de Ginástica para tais indivíduos.

- Mídia: estudo das relações entre mídia e Ginástica, considerando que a sociedade é fortemente influenciada pelos meios de comunicação de massa.

Apresentamos agora a produção do conhecimento em Ginástica, ano de 2000 até setembro de 2009, separada por dissertações de mestrado e teses de doutoramento.

\section{A BASE TEÓRICA DA PRODUÇÃO DO CONHECIMENTO EM GINÁSTICA}

\section{Fitness}

Nesta categoria foram encontradas somente dissertações, totalizando 19 (dezenove). Foram encontradas 07 (sete) dissertações relacionadas a estudos sobre os clientes, a fidelidade deles e a competitividade entre as academias. De forma geral o objetivo destes trabalhos é analisar a qualidade das academias e a satisfação dos clientes. Dentre as produções, 03 (três) dissertações analisam a Ginástica de academia com atenção ao professor, investigando os benefícios e não benefícios que a profissão traz ao professor estudam sobre o custo físico dos professores de Ginástica em seu trabalho e as transformações que ocorrem no mundo do fitness, a expansão das academias, e a necessidade de aprimoramento do professor; 05 (cinco) 
dissertações trataram de aspectos biológicos da prática de Ginástica em academia, sentido desta pratica para mulheres, lesões ocorridas pela prática de exercícios de impacto, especificamente o jump fit, custo de uma aula de ginástica localizada avaliada por meio da calorimetria indireta e estudo sobre o funcionamento do sistema respiratório após aulas de ginástica localizada com exercícios de diferentes velocidades; 01 (uma) dissertação abordou o crescimento da prática de exercícios físicos, da procura pelas academias, neste sentido o crescimento paralelo do uso de suplementos nutricionais, o objetivo do trabalho foi de investigar a prevalência do uso destes suplementos por praticantes de Ginástica de academia, bem como os fatores associados a este consumo; 01 (uma) dissertação estudou o corpo ideal na contemporaneidade com o objetivo de compreender os sentidos atribuídos ao corpo pelos adolescentes masculinos frequentadores de academias de ginástica. Investiga também os fatores motivacionais para as práticas de exercícios físicos, como também o consumo indevido de esteróides anabolizantes ou energéticos, colocando em risco a saúde física e mental desta população; 01 (uma) destas dissertações teve como objetivo averiguar a influência da prática de ginástica de academia na autoestima dos praticantes e ainda as relações de gênero entre os mesmos; 01 (uma) dissertação comparou os efeitos do treinamento de ginástica localizada e hidroginástica nos níveis de força e de V02 entre mulheres não atletas.

Com base nas produções acima verificamos que esta categoria agrega diferentes interesses dos pesquisadores, interesses estes que perpassam por questões relacionadas à profissionalidade daqueles que atuam nas academias de Ginástica; aos interesses, perfil e objetivos dos clientes que frequentam esses espaços; à proliferação das academias nos espaços urbanos, até mesmo, ao sentido que os frequentadores das academias atribuem ao seu corpo.

Dentre os diferentes interesses dos pesquisadores podemos inferir que a maior parte das produções aborda a questão da profissão do professor atuante nesses espaços o que nos leva a concluir que pesquisas qualitativas relacionadas ao sentido e significado da profissão estão sendo interesse de investigação dos profissionais da área da Educação Física.

\section{Saúde}

$\mathrm{Na}$ área da saúde, nas bases de dados em que ocorreu a pesquisa, encontramos $\mathbf{1 6}$ (dezesseis) 
dissertações e $\mathbf{0 1}$ (uma) tese. Constatamos que 12 (doze) das dissertações com seus temas ligados à Ginástica laboral. A produção deste conhecimento em sua totalidade indica os efeitos e a influência de programas de Ginástica laboral relacionados à maior disposição para o trabalho, prevenção de doenças ocupacionais e maior produtividade em empresas.

As demais dissertações: 01 (uma) trata de estudos ligados a programas de Ginástica para idosos, em que investiga a implementação de Ginástica para idosos nos centros de saúde, constatou que o programa influenciou nas aptidões físicas, como: coordenação, resistência aeróbica e força; 01 (uma) aborda os efeitos de um programa de Ginástica postural sobre indivíduos com hérnia lombar, investiga a possibilidade de como a Ginástica postural ameniza os sintomas da lombalgia, o resultado mostrou pontos positivos e negativos; 01 (uma) com objetivo de identificar os níveis de gordura corporal, atividade física e hipertensão arterial, estabelecendo relações entre essas variáveis em estudantes de 10 a 17 anos de uma determinada escola; 01 (uma) analisa os efeitos dos anabólicos e a prevalência do uso deles em praticantes de musculação numa dada cidade.

No que se refere às teses encontramos 01 (uma) que teve como objetivo analisar características de crescimento, antropometria nutricional, alterações de composição corporal e distribuição de gordura em relação à menarca de ginastas praticantes de Ginástica Rítmica de diferentes localidades do Brasil.

A ênfase dos trabalhos recai sobre a produção científica com preocupações relacionadas à Ginástica Laboral, no sentido de manter os indivíduos saudáveis para garantir ao aumento da produção nas empresas ou nos diferentes ambientes de trabalhos. Nesta direção, podemos considerar que os pesquisadores mantêm uma preocupação com os aspectos biológicos, na qual os exercícios ginásticos vão ao encontro de atender as necessidades de um corpo bem fisicamente com vistas a atender as necessidades de realização das atividades diárias dos indivíduos quer em seus ambientes de trabalhos, de treinamentos ou em seu dia-a-dia.

\section{Esportes}

No campo esportivo foram encontradas 14 (quatorze) dissertações, destas, 08 (oito) são relacionados à Ginástica Artística (GA), 05 (cinco) à Ginástica Rítmica (GR) e 01 (um) à Ginástica Aeróbica de Competição (GAE). Na categoria teses foram encontradas 02 (duas), 
01 (uma) ligada à Ginástica Artística e 01 (uma) à Ginástica Rítmica.

As dissertações que pesquisam a GA, o fazem em diversas vertentes: 01 (uma) estuda sobre a estatura de ginastas na ginástica artística feminina de alto nível no Brasil, preocupada com o comportamento motor e o desenvolvimento biológico das ginastas, aborda a questão da influencia ou não da GA no nível de crescimento de atletas; 01 (uma) é sobre a desistência da prática da GA de atletas de alto rendimento do sexo feminino no Estado do Rio Grande do Sul. O estudo analisa todos os fatores que envolvem esta desistência; 01 (uma) tem como população alvo as atletas de GA. Investiga os tipos de medos, os motivos destes medos e como as mesmas lidam com este problema. O objetivo é contribuir com as atletas, a família e os técnicos de GA, para que eles entendam o contexto psicológico das atletas e aprendam a lidar com ele. Outra dissertação é voltada para a pedagogia de treinamento, investiga como técnicos e professores atuam em relação à metodologia do ensino da GA; 01 (uma) estuda a motivação para a prática da GA e aponta os fatores principais que incentivam a prática da modalidade, como as conquistas mundiais que os atletas brasileiros têm alcançado e os patrocínios, e, também, a mídia como um dos meios mais fortes que evidenciam a GA, podendo ser considerada como grande motivadora; 01 (uma) tem como objetivo central descrever o panorama da Ginástica Artística Masculina (GAM) brasileira no último ciclo olímpico (2005-2008); 01 (uma) objetivou propor e levantar evidências da validade de uma bateria de testes físico-motores, voltada para a seleção de talentos para a GA feminina; 01 (uma) estudou a modalidade Ginástica Artística (GA), no contexto delimitado ao esporte de Alto Nível, realizando a apresentação e discussão do que seja o caráter objetivo e o subjetivo desta prática. Com relação a estes aspectos, buscou-se além da compreensão dos mesmos, entender sua relação e a importância de cada um deles perante a prática da GA, dissertando sobre as características objetivas e subjetivas desta modalidade.

Das 05 (cinco) dissertações sobre GR: 01 (uma) trata sobre a beleza e o poder que envolve a GR. Por meio de análise de regras e pontuação foram feitas reflexões sobre "beleza regulamentada", "corpo belo" e as relações com a Educação Física; 01 (uma) analisa um gesto técnico de difícil execução de forma correta na GR, o salto. Analisa o deslocamento vertical dos quatro diferentes tipos de saltos executados na GR em diferentes fases de treinamento; 01 (uma) teve como objetivo geral analisar a estruturação do processo de ensino, aprendizagem e treinamento da categoria infantil na GR e verificar o impacto deste processo no 
desenvolvimento das capacidades físico-motoras das atletas; 01 (uma) averiguou o grau de inferência, em relação à orientação espaço-temporal durante campeonatos e torneios nacionais ocorridos em 2005, das ginastas do Pré-infantil e Infantil, visando uma análise do que ocorre nas coreografias destas categorias de base em face às exigências do Código de Pontuação da Federação Internacional de Ginástica (FIG); 01 (uma) teve por objetivo identificar as características dermatoglíficas, somatotípicas e de qualidades físicas básicas de atletas brasileiras de Ginástica Rítmica de diferentes níveis de qualificação esportiva.

Encontramos 01 (uma) dissertação que aborda a Ginástica Aeróbica Esportiva (GAE), realizou-se uma pesquisa sobre modelo de excelência de treinadores experts brasileiros de ginástica aeróbica esportiva, objetivando identificar quais fatores comuns, referentes ao treinamento, foram apresentados pelos treinadores brasileiros experts de ginástica aeróbica esportiva, durante a execução de uma tarefa proposta.

No que se refere a teses temos $\mathbf{0 1}$ (uma) que trata da GA enquanto treinamento. Visa apresentar uma proposta para melhoria da preparação do técnico de GA para que haja melhor qualidade no ensino desta modalidade; E outra que tratou de propor e aplicar um programa que seja adotado no processo de ensino-aprendizagem da Ginástica Rítmica (GR), visando à estruturação de uma ação pedagógica que possibilitasse a construção do conhecimento da GR oriundo das relações e percepções sócio-culturais do ambiente em que se deu a aprendizagem.

Observamos que a categoria relacionada ao Esporte aparece como um dos grandes interesses de pesquisas dos profissionais da área, seguido das categorias Fitness e Saúde. Isso nos mostra que aspectos relacionados à aptidão física, saúde e esportes são temáticas consolidadas em nossa profissão decorrentes da hegemonia higienista, como também da concepção tecnicista presente nos diferentes momentos históricos da Educação Física em nosso país.

Considerando, especificamente, a categoria Esportes verificou-se que os interesses perpassam por diferentes aspectos ligados às modalidades de Ginástica Rítmica, de Ginástica Artística e de Ginástica Aeróbica Esportiva. Nesta direção, ao tratar das diferentes ginásticas esportivas as pesquisas abordam aspectos relacionados ao treinamento de rendimento, à técnica dos gestos e das modalidades, mas também tratam de questões que influenciam o ensino dos movimentos específicos dessas modalidades. 
Observamos também nos estudos preocupações de ordem objetivas e subjetivas que se apresentam no esporte de rendimento, tais como: desistências de ginastas em modalidades esportivas, a formação profissional de técnicos, o padrão de beleza e de corpo presente na ginástica de competição, entre outros. Isso demonstra um aumento de produções que superam preocupações somente de ordem fisiológica e biológica, manifesto no desempenho e no rendimento, apontando para aspectos qualitativos e subjetivos relacionado ao treinamento dessas modalidades.

\section{O âmbito escolar}

No que se diz respeito à categoria Escola, percebemos que na maioria dos trabalhos a preocupação é com a Ginástica enquanto conteúdo da Educação Física. Foram encontradas 08 (oito) dissertações e $\mathbf{0 1}$ (uma) tese com a temática relacionada à Escola. Quanto às dissertações: 01 (uma) tem como objeto programa postural para escolares do Ensino Fundamental. A Ginástica neste caso é apenas um instrumento, um meio de correção postural dos estudantes, não sendo considerada como conteúdo; 06 (seis) dissertações tratam da Ginástica enquanto como assunto a ser ensinado pelos professores de Educação Física, dentre elas: 01 (uma) dissertação de mestrado evidencia uma proposta de Ginástica Escolar preocupada com valores éticos e desenvolvimento do humano. Apresentam referências às questões de convívio social, as condutas desejáveis e não desejáveis nas relações entre humanos e defende a Ginástica como meio de formação humana dentro do contexto escolar; 02 (duas) dissertações pesquisam sobre as dificuldades encontradas pelo professor para inserir a Ginástica como conteúdo na escola. Uma delas discorre sobre a Ginástica de Grande Área e, outra, trata especificamente das Ginásticas Esportivas: Ginástica Artística e Ginástica Rítmica como conteúdo; 01 (uma) aborda a Ginástica Geral/Ginástica Para Todos aparece como um projeto a ser desenvolvido na escola pública, sendo que a pesquisa envolve a análise da viabilidade de um dado método para desenvolver tal projeto; e 02 (duas) estudam o significado da vivência da Ginástica para os estudantes, primeiro proporcionaram a estes estudantes a vivência da Ginástica (Geral e Rítmica) e após, através de análise qualitativa, foram identificados os significados que esta vivência teve para os participantes da pesquisa; 01 (uma) objetivou verificar as variantes relevantes nas ações de três professores de Educação Física de três escolas do Ensino Fundamental, nos quadrantes administrativo, pedagógico e motivacional, na aplicação de uma proposta alternativa para a prática da Ginástica Rítmica 
nas aulas de Educação Física, bem como, analisar as manifestações dos alunos de neste processo de aprendizagem.

A única tese encontrada nesta categoria discorre sobre a Ginástica na escola e na formação de professores, seu eixo central discute a inclusão/exclusão do conteúdo Ginástica nas aulas de Educação Física.

Nesta categoria notamos a preocupação dos pesquisadores com a questão que afeta a Ginástica como conteúdo curricular das aulas de Educação Física. Nesta direção, defendem a Ginástica Postural, as Ginásticas Esportivas (Artística, Rítmica e Aeróbica) e a Ginástica Geral como conteúdos relevantes a serem ensinados nas aulas de Educação Física nos diferentes níveis da educação básica. As pesquisas revelam também preocupações com o desenvolvimento humano e valores éticos.

Para tal, a inclusão da Ginástica nas aulas de Educação Física perpassa primeiramente pela forma como esse conteúdo está sendo ensinado nos cursos de formação de professores nas diferentes universidades. O objeto de estudo da tese atenta-se que a inclusão desses saberes ginásticos devem ser ressignificados nos cursos de formação inicial de professores.

\section{Lazer e Qualidade de Vida}

Nas bases de dados em que ocorreu a pesquisa, encontramos 04 (quatro) dissertações nesta categoria. Referente a esta temática temos 01 (uma) dissertação cujo título é: As possibilidades de limites da Ginástica no campo do lazer. O estudo apresenta subsídios para a construção de uma proposta metodológica de ensino da ginástica escolar que contempla seu aspecto lúdico, levando-se em conta as especificidades dos conteúdos da mesma. Assim, busca legitimar a presença da ginástica no currículo da Educação Física, numa perspectiva crítica de educação, buscando promovê-la através de um espaço amplo de liberdade para que os alunos possam vivenciar as próprias ações corporais de forma prazerosa, dando sentido às mesmas; 01 (uma) dissertação trouxe o tema qualidade de vida, a preocupação da autora foi de investigar possíveis encontros ou aproximações da qualidade de vida com a Educação Física através da Ginástica Geral; 01 (uma) dissertação procurou identificar quais os efeitos da ginástica de academia na qualidade de vida de mulheres de trinta e cinco (35) a cinquenta (50) anos, que praticam a ginástica por mais de (06) meses; 01 (uma) dissertação trata da 
Ginástica Geral, estuda a questão dos conceitos e definições a respeito da Ginástica Geral e leva em conta a observação e percepção de professores e praticantes envolvidos com a modalidade.

A partir das análises das dissertações nesta categoria infere-se que as práticas gímnicas estão aliadas a situações de lazer e de qualidade de vida configurando-se em dois aspectos: o primeiro ressalta a intervenção da Ginástica de modo prazeroso e criativo, contribuindo para que ela se consolide entre as opções de lazer, sendo a escola um espaço adequado para a apreensão de conhecimentos que gerem experiências lúdicas. O segundo aspecto, foca as atividades ginásticas de academia predominantemente voltadas para a busca da melhoria da saúde e da aptidão física, no sentido de que corpo saudável está diretamente relacionado a uma boa qualidade de vida.

\section{Aspectos Históricos}

Nesta categoria foram encontradas $\mathbf{0 3}$ (três) dissertações e $\mathbf{0 2}$ (duas) teses, os trabalhos têm como objetivo comum analisar o percurso da Ginástica em diferentes localidades, suas transformações, as consequências do passado para o presente.

No tocante às produções das dissertações temos: 01 (uma) em que trata da temática: A prática do Turnen na cidade de São Paulo. O estudo contextualiza a Alemanha, a derrota para o exército napoleônico, o ideal de revanche, o preparo da mocidade para outra possível batalha. Assim, Johann Friedrich Jahn criou o Turnen, manifestação gímnica de caráter patriota que abrangia todo tipo de exercício físico. O trabalho avaliou a difusão do Turnen entre os brasileiros e os imigrantes, identificando as contribuições de sua prática em São Paulo; 01 (uma) dissertação investiga a ginástica em campinas: suas formas de expressão da década de 20 a década de 70. Este trabalho também analisa o percurso da Ginástica desde sua entrada no Brasil e a escolha deste período ocorreu devido às modificações em várias áreas e, também, do conceito de Ginástica tanto na escola, como nas academias e nas universidades; 01 (uma) objetiva reconstruir a história da Ginástica Rítmica em Campinas - São Paulo - Brasil, a autora justifica que este tema nunca foi explorado em pesquisas acadêmicas e afirma que esta é sem dúvida uma grande história, a história de vida de pessoas que passaram por esse esporte e deixaram marcas de conquistas, vitórias e paixões.

Das teses analisadas temos: 01 (uma) em que trata-se da história da Ginástica no Rio de 
Janeiro e dialoga com todos os tipos de produções científico-culturais com objetivo de entender o percurso da Ginástica do final de século XXI até início do século XX. E outra tese teve o propósito de conhecer o processo de formação desportiva das atletas brasileiras participantes de Jogos Olímpicos, na modalidade de Ginástica Artística Feminina, de 1980 a 2004.

Pela análise das pesquisas tanto de mestrado como de doutorado verificamos que a ginástica sempre esteve presente na sociedade. Os pesquisadores compreendem a relevância do conhecimento histórico das ginásticas. Notamos em 01 (um) trabalho a influência dos métodos europeus no Brasil, especificamente, o alemão, e também, a consolidação da Ginástica em diferentes localidades e épocas em nosso país. A produção em pesquisas históricas de modo contextualizado favorece a disseminação do patrimônio cultural da Ginástica.

\section{Formação Humana}

Nesta categoria foram encontrados 02 (duas) pesquisas, sendo 01 (uma) dissertação e 01 (uma) tese.

Quanto à dissertação temos 01 (uma) com objetivo de Contribuir para a formação humana dos adolescentes da Fundação Estadual para o Bem Estar do Menor (FEBEM) por meio da Ginástica Geral. Implantaram na unidade de Araraquara/SP propostas pedagógicas de Ginástica Geral que ensinou valores humanos de convivência social adequada para a reinserção social dos adolescentes reclusos.

Quanto à tese: 01 (uma) pesquisa a formação humana e a ginástica geral da Educação Física. Objetivou compreender a importância do conceito formação humana como necessário ao desenvolvimento humano em qualquer dos seus âmbitos e/ou níveis de educação. Apresenta proposta pedagógica baseada na Ginástica Geral (GG) e sua relação com a visão multicultural do currículo Os níveis estão atrelados ao reconhecimento de cultura patrimonial dos alunos a partir da qual a informação pode-se transformar em conhecimento ajudando transcender a individualidade. A pesquisa enfatiza a formação humana nos processos de ensino uma vez que por meio dela orienta o ser humano para uma sociedade mais justa e respeitosa das diferenças. 
Da produção analisada observamos que entre os diferentes tipos de Ginástica existentes em nossa sociedade a Ginástica Geral, agora denominada Ginástica Para Todos, defende em seus objetivos a formação humana, possibilitando ensinar valores humanos de convivência social. As orientações pedagógicas da Ginástica Geral podem ser uma alternativa para colaborar na educação do ser humano, considerando a aquisição de conhecimentos, a experiência motora e a construção de valores e princípios éticos.

\section{Formação Profissional}

Nesta categoria foram analisados 04 (quatro) estudos, sendo 02 (duas) dissertações e 02 (duas) teses. Quanto às dissertações: 01 (uma) dissertação aborda a temática: A Ginástica rítmica na corporeidade dos acadêmicos de Educação Física: Relações entre o pensar, falar e agir com o corpo, em que analisa como os acadêmicos percebem-se, as relações que estabelecem corporalmente, e as contribuições que a GR pode oferecer enquanto disciplina do currículo do curso. E a outra, traz como problemática significativa do estudo o trato com o conhecimento da Ginástica, na organização do trabalho pedagógico, no campo da formação inicial.

No que se refere às teses: 01 (uma) tese preocupou-se com: A Ginástica como área de conhecimento na formação profissional em Educação Física: Encaminhamentos para uma reestruturação Curricular com objetivo de investigar os saberes gímnicos necessários à atuação profissional, construção de uma proposta de estruturação da área de conhecimento da Ginástica para os currículos dos Cursos de Educação Física. Apresentou uma proposta para melhor estruturação do currículo do curso de Educação Física, sustentada numa base teórica que propõe estabelecer as relações com a formação inicial e as necessidades emergentes na sociedade. E 01 (uma) teve como objetivo apresentar uma proposta que visa melhorar a qualidade de ensino da Ginástica Artística (GA), partindo-se da premissa que existe a necessidade de uma formação específica para os professores de Educação Física que querem atuar como técnico dessa modalidade.

Podemos inferir que o objeto de preocupação dos pesquisadores nesta categoria envolvem inquietações relacionadas aos saberes gímnicos necessários à atuação profissional, quer em escolas, clubes ou academias. Nesta direção é importante considerar os cursos de formação 
profissional (universidades) responsáveis pelo repensar os seus cursos, bem como, os pressupostos e os fundamentos de seus currículos. Destacam a necessidade da construção de propostas de estruturação da área de conhecimento da Ginástica para os currículos dos cursos de Educação Física.

\section{Necessidades Especiais}

Foram encontrados 02 (dois) trabalhos desta temática, sendo 01 (uma) dissertação e 01 (uma) tese. Das dissertações analisadas encontramos 01 (uma) que forneceu subsídios para uma intervenção motora no contexto da deficiência visual, objetivando sugerir duas medidas de intervenção que auxiliem na questão da falta de preparo dos professores de Educação Física para intervir com esta população. Primeira, a construção de um guia de avaliação oftalmológica direcionado a professores de Educação Física que trabalham com alunos com deficiência visual, com o intuito de aproximar a linguagem e a interação das áreas de Educação Física e de Oftalmologia. Segunda, proposta pedagógica do ensino da Ginástica Artística para crianças com Deficiência Visual.

No que se refere às teses $\mathbf{0 1}$ (uma) delas investiga os efeitos dos treinos físicos e mentais do ensino do rolamento para frente em alunos com deficiência mental, com o objetivo de verificar se o ensino de habilidades motoras: rolar, auxilia as pessoas com deficiência mental. O resultado do treino mental foi positivo e este compreendeu possibilitar ao aluno o entendimento do movimento através da imaginação o que facilitou realizar o treino físico, que seria o movimento em si.

As pesquisas encontradas em Ginástica articuladas com a temática: Pessoas com Necessidades Especiais perpassaram por questões que investigam os efeitos do treino quando do ensino de uma dada habilidade, no caso específico, o rolamento. E também, aspectos que questiona a falta intervenção de professores. As políticas públicas tem considerado o atendimento especializado às Pessoas com Necessidades especiais em diversos setores da sociedade e este atendimento deve integrar a proposta pedagógica da escola, provendo condições de acesso, participação e aprendizagem na educação básica. Faz-se necessário a ampliação de estudos e pesquisas nesta temática, pois há qualificar e aumentar a oferta de atendimento educacional especializado no âmbito da Educação Física, manifesto em seus conteúdos estrururantes, no caso dos jogos, das lutas, do esporte, da dança e da ginástica. 


\section{Mídia}

Encontramos 01 (uma) dissertação que trata do discurso midiático da Ginástica Artística. O objetivo foi analisar os conteúdos veiculados pela mídia sobre a GA, identificando os valores e ideologias presentes nos mesmos em relação à GA. Feita esta análise constatou-se que o mundo do esporte na televisão incorporou os valores do mercado, fazendo a espetacularização para atrair multidões para este fenômeno.

Observamos poucos trabalhos que tratam de Ginástica e mídia. Ressaltamos a relevância deste tipo de pesquisa porque desvela que os meios de comunicação de massa, nomeadamente, a televisão, tem a tendência a veicular a Ginástica Artística somente como esporte espetáculo e elitizado, em que mostram os treinos, os sacrifícios dos ginastas, o corpo belo e as grandes performances. Os meios de comunicação deixam de revelar que essa modalidade não é acessível somente aos grandes ginastas, ela pode ser praticada tendo em vista os objetivos educacionais e de participação primando para uma melhor qualidade de vida, lazer e saúde.

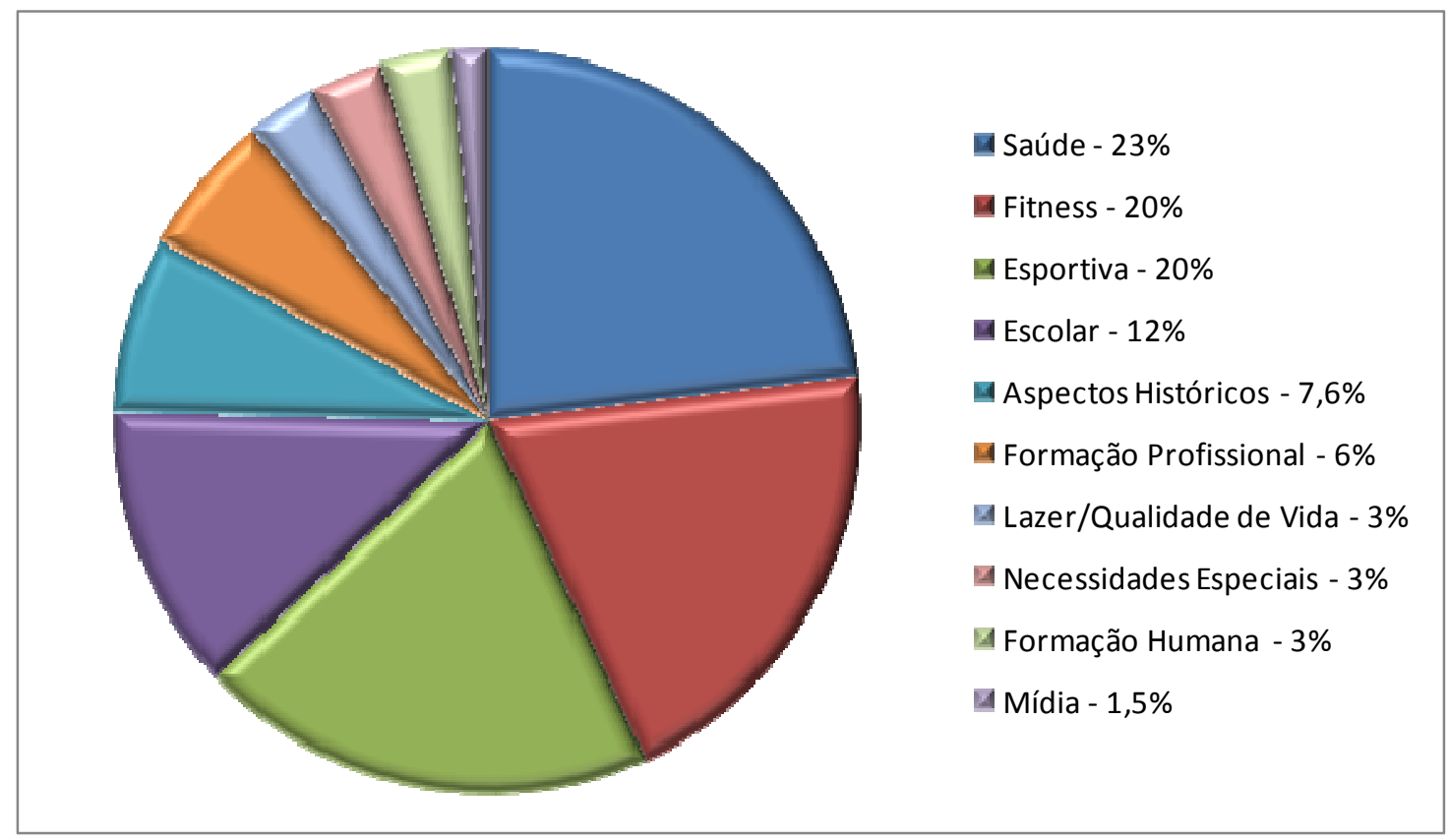

Gráfico 1: Produção do conhecimento em Ginástica.

\section{CONSIDERAÇÕES PROVISÓRIAS}

Nada é passível de ser concluído com exatidão, pois não há pesquisa que esgote um tema

Conexões: revista da Faculdade de Educação Física da UNICAMP, Campinas, v. 10, n. Especial, p. 56-79, dez. 2012.75 ISSN: 1983-9030 
científico, ou seja, não existem respostas fixas e acabadas para a indagação que foi inicialmente elaborada.

Esta pesquisa investigou a produção do conhecimento na área de Educação Física, especificamente em Ginástica, tendo como referência as dissertações de mestrado e as teses de doutorado produzidas em nível nacional, disponíveis nas bases de dados da Biblioteca Digital de Teses e Dissertações (BDTD), Biblioteca Digital da Unicamp, Sistema de Publicação Eletrônica de Teses e Dissertações (NUTESES) e Biblioteca Digital de Teses e Dissertações da USP. A pesquisa realizada nestas bases de dados objetivou levantar o maior número possível de produções em relação à temática Ginástica para obter um resultado mais próximo possível do real. Lembramos que muito mais pode ter sido produzido e não publicado em bibliotecas e bancos virtuais.

Identificamos que a Ginástica está ligada a diferentes interesses, tendo vários objetivos e finalidades sociais, o que ficou demonstrado nas temáticas encontradas: Saúde; Fitness, Esportes; Escola; Aspectos Históricos; Formação Profissional; Lazer e Qualidade de Vida; Necessidades Especiais e Mídia.

Considerando as características indicadas pelas dissertações analisadas pode-se balizar como está a produção do conhecimento em Ginástica. A maioria dos trabalhos se concentra na área da Saúde com muitos estudos realizados sobre a Ginástica laboral e as academias de Ginástica. A Ginástica desde sua gênese na Grécia está ligada à concepção de saúde, na medicina de Galeno, e nos tempos contemporâneos também tem sido altamente considerada no âmbito acadêmico. Esta concepção está atrelada a uma matriz biológica que concebe a Educação Física na perspectiva de saúde e de atividade física. E a força desta vertente está presente estimulando a produção científica em torno deste assunto.

Grande parte da produção se atém ao mundo do Fitness, sendo a maioria dos estudos focados no mercado de trabalho, pois trata de investigar a qualidade das academias e a fidelidade dos clientes. Este aspecto evidencia a Ginástica tratada como negócio. Observamos também preocupação com os benefícios da Ginástica e com a satisfação dos professores. A compreensão dos freqüentadores do mundo do Fitness muitas vezes está ligada ao senso comum, porque saúde, estética e beleza do corpo se torna um sonho e uma meta irrefletida. As 
academias de ginástica reforçam a concepção de corpo reduzida à saúde, ao corpo perfeito e belo, divulgado pela mídia, ou seja, elas reforçam o ideal capitalista e fortalecem a indústria do corpo. Observamos que a maioria das produções nesta temática reforça essa concepção e entre os trabalhos analisados somente um apontava na direção crítica do modelo de corpo padronizado na sociedade atual.

A produção da Ginástica no que refere ao Esporte visa colaborar e instrumentalizar os profissionais, as elites dirigentes, a alcançarem o sucesso e a performance. As pesquisas estão ligadas aos aspectos de aprendizado e treino, comportamento motor, beleza e técnica de execução de movimentos, superação dos medos das atletas, o porquê da desistência das atletas e, também na formação de treinadores experts.

Deparamos também com produções relacionando o tema Esporte e Mídia, em que o esporte incorpora os valores do mercado, fazendo a espetacularização para atrair multidões para este fenômeno.

A área escolar produziu um número considerável de pesquisa sobre a Ginástica na escola. Percebemos preocupações com a inclusão da Ginástica enquanto conhecimento a ser tratado na escola pela Educação Física e não apenas como rol de atividades com fim em si mesmo. As pesquisas nestas direções demonstram avanços para a educação, porque esta disciplina está para além do físico tão só, do biológico. Isso pode significar um avanço, traduzido numa concepção ligada à motricidade e a complexidade.

As produções que convergem com o âmbito educacional são as de Formação Humana. Estas produções consideram a Ginástica na perspectiva de conhecimento a ser apreendido na educação e na formação da pessoa. A educação e formação podem ocorrer nos diversos níveis do ambiente educacional ou também fora dele, como é o caso especifico de ações na Fundação Estadual para o Bem Estar do Menor (FEBEM), atualmente denominado Fundação Casa.

Cabe ressaltar que temos produção, embora de número reduzido, com preocupações de ordem metodológica do ensino da Ginástica Escolar que contempla o lúdico e a educação para o lazer. A concepção de Ginástica aponta para uma perspectiva crítica de educação, buscando Conexões: revista da Faculdade de Educação Física da UNICAMP, Campinas, v. 10, n. Especial, p. 56-79, dez. 2012.77 ISSN: 1983-9030 
promovê-la através de um espaço amplo de liberdade para que os alunos possam vivenciar as próprias ações corporais de forma prazerosa.

A produção de pesquisas em Aspectos Históricos revela a atenção para privilegiar a história no percurso de contextualização do passado e da transformação que engloba o presente, pois as análises das condições passadas permitem avaliar o presente e projetar o futuro.

No âmbito da produção de conhecimento em Ginástica observamos dois movimentos, um no sentido em que os estudos estão sob a influência da biologização, sob o paradigma positivista e atrelados a aspectos quantitativos, traduzidos em pesquisas do comportamento motor e dos aspectos mais técnicos das modalidades ginásticas e tem por objetivo, aptidão física, beleza e performance, nomeadamente, as pesquisas ligada à área da Saúde, do Fitness e dos Esportes.

Outro, no sentido mais abrangente, complexo, em que revela tendências de uma concepção crítica e superadora, traduzidos em questões referentes à educação e a formação humana, que são as pesquisas referentes a Escola, Aspectos Históricos, Formação Profissional, Lazer e Qualidade de Vida, Necessidades Especiais e Mídia.

\section{REFERÊNCIAS}

${ }^{1}$ CESARIO, M.; PEREIRA, A. M. Reflections about gymnastic in different contexts. Fiep Bulletin, Foz do Iguaçu, v.78, p. 68-70, 2008.

${ }^{2}$ GIL. A. C. Como elaborar projetos de pesquisa. São Paulo: Atlas, 1988.

${ }^{3}$ BARDIN, L. Análise de conteúdo. Lisboa: Edições 70, 1977.

${ }^{4}$ CAPES. Coordenação de Aperfeiçoamento de Pessoal de Nível Superior. Portal de Periódicos da CAPES. Disponível em <http://www.periodicos.capes.gov.br>. Acesso em: 30 set. 2010.

${ }^{5}$ BDTD. Biblioteca Digital de Teses e Dissertações. Disponível em <http://bdtd.ibict.br/>. Acesso em: 24 maio 2011.

${ }^{6}$ BIBLIOTECA DIGITAL DA UNICAMP. Universidade Estadual de Campinas. Disponível Conexões: revista da Faculdade de Educação Física da UNICAMP, Campinas, v. 10, n. Especial, p. 56-79, dez. 2012.78 ISSN: $1983-9030$ 
em: <http://bibliotecadigital.unicamp.br/ >. Acesso em: 10 fev. 2011.

${ }^{7}$ NUTESES. Núcleo Brasileiro de Dissertações e Teses. Sistema de Publicação Eletrônica de Teses e Dissertações. Disponível em: 〈http://www.nuteses.ufu.br/>. Acesso em: 24 maio 2011 .

${ }^{8}$ BIBLIOTECA DIGITAL DE TESES E DISSERTAÇÕES DA USP. Universidade de São Paulo. Disponível em <http://www.teses.usp.br/>. Banco de Dados Bibliográficos da USP. Catálogo Online Global DEDALUS. Disponível em: <http://dedalus.usp.br:4500/ALEPH/por/USP/USP/DEDALUS/START>. Acesso em: 20 set. 2011.

${ }^{9}$ SOUZA, E. P. M. Ginástica geral: uma área do conhecimento da educação física. 1997. 163 f. Tese (Doutorado em Educação Física)-Faculdade de Educação Física, Universidade Estadual de Campinas, Campinas, 1997. 